Arq. Bras. Med. Vet. Zootec., v.65, n.6, p.1867-1875, 2013

\title{
Características de carcaça de cabritos criados em dois sistemas de terminação
}

\author{
[Carcass characteristics of goat kids in two finishing systems] \\ F.M. Salles ${ }^{1}$, M.A. Zambom ${ }^{1}$, C.R. Alcalde ${ }^{2}$, F.A.F. Macedo ${ }^{2}$, R. Souza ${ }^{2}$, L.C. Gomes ${ }^{2}$, \\ F.B. Dias $^{2}$, B.S.L. Molina ${ }^{2}$ \\ ${ }^{1}$ Universidade Estadual do Oeste do Paraná - M.C. Rondon, PR \\ ${ }^{2}$ Universidade Estadual de Maringá - Maringá, PR
}

\begin{abstract}
RESUMO
Avaliaram-se as características da carcaça de cabritos Saanen confinados, Saanen e 7/8 Boer - 1/8 Saanen semiconfinados, bem como a influência de grupo genético e sistema de terminação sobre o rendimento comercial, índice de compacidade, não constituintes, área de olho de lombo, força de cisalhamento, gordura, teor de umidade e teor de extrato etéreo. Utilizaram-se 31 machos inteiros, com aproximadamente 128 dias de idade e 22,9 $\pm 2,4 \mathrm{~kg}$ de peso vivo. Destes, 22 eram da raça Saanen e nove animais eram mestiços 7/8 Boer - 1/8 Saanen. Os animais da raça Saanen foram divididos em dois grupos de 11 animais, sendo um grupo mantido em confinamento e outro em semiconfinamento, enquanto os mestiços foram mantidos em semiconfinamento. Compararam-se os sistemas de terminação na raça Saanen, e os grupos genéticos no sistema semiconfinado. Os animais confinados receberam 3,5\% do PV em ração completa peletizada; os semiconfinados tiveram acesso à pastagem e suplementação de 1,5\% do PV em ração concentrada peletizada. Aos 47 dias de terminação, os animais foram abatidos e as características de carcaça determinadas por meio de uma amostra de lombo dissecado. Foram observadas diferenças entre sistemas de terminação para rendimento comercial de carcaça, índice de compacidade da carcaça, não constituintes de carcaça, área de olho de lombo, força de cisalhamento, gordura, teor de umidade e de extrato etéreo. Entre os grupos genéticos, foram observadas diferenças para área de olho de lombo, espessura de gordura e matéria mineral. O sistema de terminação exerceu influência sobre as características de carcaça avaliadas. A raça Saanen pode ser utilizada para a produção de carne quando submetida ao confinamento.
\end{abstract}

Palavras-chave: caprino, carne, sistema de terminação, longissimus dorsi

\begin{abstract}
Was evaluated carcass characteristics of feedlot goats Saanen, Saanen and 7/8 Boer - 1/8 Saanen semiconfined, as well as the influence of the genetic groups and finishing systems on the commercial performance, compactness index, not constituents, area ribeye, shear force, fat, moisture and ether extract content. Were used 31 bulls, with approximately 128 days of age and 22.9 $\pm 2.4 \mathrm{~kg}$ live weight $(L W)$. Of these, 22 were Saanen, and nine animals were crossbred 7/8 Boer - 1/8 Saanen. The Saanen animals were divided into two groups of 11 animals each, one group and another kept in a feedlot in semiconfinement, while crossbreds were kept in semiconfinement. Was compared the finishing systems in Saanen, and genetic groups in semi-confined system. The confined animals received $3.5 \%$ of $L W$ in complete pelleted ration, the semiconfinados had access to pasture and supplementation of $1.5 \%$ of $L W$ in pelleted concentrate ration. At 47 days of terminating the animals were slaughtered and the carcass characteristics determined using a sample loin dissected. Differences were observed between finishing systems for commercial carcass yield, carcass compactness index, not constituents carcass, loin eye area, shear force, fat, moisture and ether extract. Between genetic groups, differences were observed for ribeye area, fat thickness and mineral matter. The finishing system exerted influence on carcass traits evaluated. The Saanen can be used for the production of meat when subjected to confinement.
\end{abstract}

Keywords: caprine, meat, finishing system, longissimus dorsi

Recebido em 2 de abril de 2013

Aceito em 12 de setembro de 2013

E-mail: fmsalles.vet@hotmail.com. 


\section{INTRODUÇÃO}

Dentre os componentes da carcaça, o que se destaca no interesse do consumidor é a carne. A qualidade da carne é um conceito relativo, podendo ser definida estritamente em termos físicos e químicos, ou em termos da percepção pelo consumidor. Os constituintes da qualidade são descobertos e redefinidos continuamente.

Dentre os constituintes da qualidade, destacamse as características anatômicas e a composição química, as quais contribuem para uma definição mais ampla da qualidade da carne, envolvendo características como palatabilidade, salubridade e ausência de patógenos e toxinas. Cada um desses critérios é condicionado a fatores biológicos que incluem o gênero e a idade, e fatores não biológicos, como estresse pré-abate, técnicas de abate, e métodos de resfriamento e congelamento da carcaça. A palatabilidade é afetada diretamente pelo estado fisiológico do animal vivo e pelos teores de gordura e tecido conjuntivo presentes na carcaça (Casey e Webb, 2010).

Além dos condicionantes citados, em cabritos o desempenho e as características da carcaça são influenciados diretamente pela composição nutricional da dieta, sendo a suplementação com concentrado uma ferramenta importante para o aproveitamento da dieta total, quando se tem disponibilidade de pastagem (Carvalho Jr. et al., 2009).

Raças caprinas usadas na produção de leite, como a Saanen, podem apresentar uma menor cobertura muscular em relação às raças produtoras de carne, como a Boer; porém, se submetidas a um manejo nutricional adequado, podem atingir ganhos de peso satisfatórios e imprimir uma boa conformação da carcaça, justificando o uso do macho dessa raça para produção de carne, complementando a renda do sistema leiteiro (Costa et al., 2008).

Segundo Mahgoub e Lodge (1998), a comparação entre os componentes corporais de animais de diferentes tamanhos é sempre difícil. Diversos critérios são sugeridos para essa comparação, incluindo idade, peso corporal, peso ao nascer, peso da carcaça e níveis de gordura. Do ponto de vista comercial, alguns consumidores preferem uma carcaça com maior peso, dando menor importância a tamanho ou sexo, enquanto outros preferem a maciez em vez de outras características.

Nesse contexto, objetivou-se com este estudo avaliar as características quantitativas e qualitativas da carcaça de cabritos Saanen terminados em confinamento, Saanen e 7/8 Boer - 1/8 Saanen terminados em semiconfinamento, bem como a influência de grupo genético e de sistema de terminação sobre as carcaças.

\section{MATERIAL E MÉTODOS}

$\mathrm{O}$ experimento foi realizado entre outubro e dezembro de 2009, utilizando-se 31 caprinos, machos inteiros, das raças Saanen (22 animais) e mestiços 7/8 Boer - 1/8 Saanen (nove animais), com idade média de 120 dias e peso vivo (PV) inicial de $23 \pm 2,4 \mathrm{~kg}$ e final de $29 \pm 3,6 \mathrm{~kg}$. O período experimental foi de 47 dias, e os animais foram pesados, em jejum prévio de sólidos de 12 horas, na instalação do experimento, e a cada 14 dias, para acompanhamento do peso vivo e ajuste do fornecimento de ração.

Os animais foram separados em três grupos, distribuídos em um delineamento inteiramente ao acaso, sendo: 11 animais da raça Saanen mantidos em confinamento, 11 animais da raça Saanen mantidos em semiconfinamento e nove animais mestiços 7/8 Boer - 1/8 Saanen mantidos em semiconfinamento. Para o estudo dos efeitos dos sistemas de terminação, os animais Saanen confinados foram comparados com os animais da mesma raça mantidos em semiconfinamento. Já para o estudo dos grupos genéticos, os animais Saanen semiconfinados foram comparados com os animais mestiços $7 / 8$ Boer - 1/8 Saanen também mantidos em semiconfinamento.

Durante o ensaio, os animais permaneceram alojados em galpão coberto e com piso ripado suspenso, em baias coletivas, com disponibilidade de água e comedouros, porém separados em confinados e semiconfinados. No confinamento os animais receberam ração total peletizada, a qual era fornecida às $8 \mathrm{~h}$ e $16 \mathrm{~h}$, segundo um consumo estimado em $3,5 \%$ do peso vivo. A ração total possuiu relação volumoso:concentrado de 30:70, contendo como volumoso o feno de Tifton (Cynodon spp cv Tifton 85). Os animais semiconfinados possuíam 
acesso à pastagem de grama-estrela (Cynodon nlemfuensis), na qual foi determinada a oferta de matéria seca e a composição químicobromatológica e a carga animal foi ajustada para assegurar o consumo de volumoso de $1,5 \%$ do PV. Os animais eram mantidos na pastagem das $8 \mathrm{~h} 30 \mathrm{~min}$ até às $16 \mathrm{~h}$, e ao retornarem da pastagem eram suplementados com ração concentrada (1,5\% do PV), peletizada. As rações (Tab. 1) foram formuladas segundo as exigências do AFRC (Agricultural..., 1995), com 15\% de proteína bruta e $70 \%$ de nutrientes digestíveis totais.

Tabela 1. Composição percentual e químicobromatológica (\%MS) das rações experimentais

\begin{tabular}{lcc}
\hline \multicolumn{1}{c}{ Alimento } & RSF & RCF \\
\hline Milho & 58,44 & 48,55 \\
Farelo de soja & 20,21 & 10,17 \\
Levedura & 18,63 & 9,39 \\
Núcleo mineral & 2,72 & 1,89 \\
Feno de tifton & ------ & 30,00 \\
\hline Matéria seca (\%) & 90,58 & 93,89 \\
Matéria orgânica (\%MS) & 94,32 & 95,09 \\
$\begin{array}{l}\text { Cinzas (\%MS) } \\
\text { Proteína bruta (\%MS) }\end{array}$ & 5,68 & 4,91 \\
Extrato etéreo (\%MS) & 17,55 & 15,02 \\
Fibra em detergente neutro & 1,68 & 1,56 \\
(\%MS) & 21,25 & 38,20 \\
Fibra em detergente ácido & 6,49 & 16,95 \\
(\%MS) & & 78,51 \\
$\begin{array}{l}\text { Carboidratos totais (\%MS) } \\
\text { Energia metabolizável }\end{array}$ & 75,10 & 2,44 \\
(Mcal kg ${ }^{-1}$ MS) & 2,70 &
\end{tabular}

RSF: ração sem feno, fornecida aos animais semiconfinados; RCF: ração com feno, fornecida aos animais confinados.

Para avaliação das características qualitativas e quantitativas da carcaça, o abate foi realizado ao final dos 47 dias do período experimental, tomando-se os pesos antes e após o jejum, para obtenção do peso corporal ao abate. No abate os animais em jejum de sólidos de 16 horas, e hídrico de 8 horas, foram pendurados pelas pernas, dessensibilizados com descarga elétrica a 220 Volts por 8 segundos, sangrados pela secção das veias jugulares e artérias carótidas direita e esquerda, esfolados e eviscerados. Após a evisceração, o trato gastrintestinal foi esvaziado para a determinação do peso corporal vazio (peso corporal ao abate menos o peso do conteúdo gastrintestinal), a fim de se obter o rendimento verdadeiro de carcaça (RVC), que corresponde à relação entre o peso da carcaça quente e o peso corporal vazio (Osório, 1992). Para determinação da porcentagem em relação ao peso corporal ao abate, foram coletados: cabeça, pés, sangue, pele, rins em conjunto com a gordura perirrenal, fígado, coração, baço, aparelho reprodutor em conjunto com a bexiga vazia e aparelho respiratório. Ao final as carcaças foram pesadas para obtenção do peso da carcaça quente, envoltas por saco plástico e transportadas para câmara fria a $4^{\circ} \mathrm{C}$, onde permaneceram penduradas pelos tendões calcâneos em ganchos apropriados para a manutenção das articulações tarsometatarsianas, distanciadas em aproximadamente $17 \mathrm{~cm}$, por um período de 24 horas.

Após o período de 24 horas, foram mensurados: o comprimento da perna, distância entre o períneo e o bordo anterior das superfícies articulares tarsometatarsianas; comprimento interno da carcaça, distância máxima entre o bordo anterior da sínfise isquiopubiana e o bordo anterior da primeira costela em seu ponto médio; largura da garupa, largura máxima entre os trocânteres de ambos os fêmures, delimitada por um compasso e medida em fita métrica; índice de compacidade da carcaça, sendo o peso da carcaça fria dividido pelo comprimento interno da carcaça; e índice de compacidade da perna, largura da garupa dividida pelo comprimento da perna.

Foi realizado um corte transversal do músculo Longissimus dorsi (entre a última vértebra torácica e a primeira lombar, no corte denominado lombo), tendo o contorno delineado com o uso de papel transparência e caneta própria, sendo em seguida utilizado o programa computacional Image-Pro Plus ${ }^{\circledR}$ (Media Cybernetics, 2002) para determinar a área de olho de lombo (AOL).

No músculo Longissimus dorsi também foram realizadas, com auxílio de um paquímetro, as seguintes mensurações: Medida A - distância máxima no corte transversal do músculo Longissimus dorsi, no sentido centro-lateral da coluna vertebral; Medida B - distância da profundidade do músculo Longissimus dorsi, no sentido dorso-ventral do animal, perpendicular à medida A; Medida $\mathrm{C}$ ou espessura da gordura de cobertura - espessura de gordura sobre a secção do Longissimus dorsi, tomando a continuação da medida B; e Medida $\mathbf{J}$ - espessura máxima de gordura de cobertura no perfil do lombo. 
O lombo da meia carcaça esquerda foi dividido em duas partes, sendo a primeira amostra utilizada para a dissecação e obtenção das proporções de gordura, osso e músculo. Foi realizado o somatório dos componentes - osso + músculo + gordura + outros - , obtendo-se o peso do corte corrigido, para o cálculo das percentagens dos componentes. Dessa primeira amostra, o músculo Longissimus dorsi foi separado e utilizado para a determinação da perda de peso por cocção, sendo as amostras pesadas, embrulhadas individualmente em papel alumínio e assadas em chapa aquecedora a $170^{\circ} \mathrm{C}$ até atingirem a temperatura interna de $70^{\circ} \mathrm{C}$ no centro geométrico das amostras, sendo a temperatura monitorada por termômetro do tipo espeto. Quando atingiram a temperatura adequada, as amostras foram retiradas da chapa aquecedora, secas em papel absorvente e esfriadas até atingirem temperatura ambiente, quando foram novamente pesadas. A diferença de peso antes e depois do cozimento resulta na porcentagem de peso perdido durante a cocção (Abularach et al., 1998).

As amostras de Longissimus dorsi cozidas foram usadas para determinar a força de cisalhamento segundo a metodologia de Wheeler et al. (2007), sendo estas cortadas longitudinalmente, no sentido das fibras musculares, na forma de paralelepípedos, num total de três subamostras utilizadas no texturômetro Stable Micro System TA-XT2i TA-XT2i Stable..., (1997), acoplado numa probe Warner-Bratzler Shear Force, com velocidade de $20 \mathrm{~cm} / \mathrm{min}$, tendo a medida da força de cisalhamento da amostra expressa em quilograma-força (kgf). A segunda amostra do lombo, armazenada em freezer a $-18^{\circ} \mathrm{C}$ até o início das análises, foi descongelada por 24 horas em geladeira, com o músculo Longissimus dorsi dissecado, triturado em processador de alimentos e utilizado para as análises de composição centesimal.

As análises de proteína bruta foram realizadas com as amostras in natura, pelo método semimicro Kjedahl, seguindo a metodologia descrita em Silva e Queiroz (2002). As amostras restantes foram secas em estufa a $55^{\circ} \mathrm{C}$ por 72 horas, trituradas em moinho tipo bola e em seguida analisadas quanto aos teores de umidade, cinzas e extrato etéreo, segundo os procedimentos descritos em Silva e Queiroz (2002).

A análise estatística foi realizada por meio de contrastes de médias, através da análise de variância e conclusiva, com o auxílio do software SAEG (Sistema..., 1997), utilizando o nível de significância a 5\%.

\section{RESULTADOS E DISCUSSÃO}

Foram observadas diferenças significativas $(\mathrm{P}<0,05)$ para o peso vivo ao abate (em jejum), para o peso de carcaça quente (Tab. 2), com a superioridade dos animais terminados em confinamento. Entre grupos genéticos não foram observadas diferenças significativas $(\mathrm{P}>0,05)$, demonstrando que o sistema de confinamento permite a terminação de cabritos Saanen com carcaça mais pesada. $\mathrm{O}$ peso em jejum é a forma mais confiável de avaliar o peso do animal vivo, por diminuir as variações decorrentes das diferenças no conteúdo do trato digestório, o qual é influenciado pelo tipo de alimento e sistema de alimentação (Yáñez et al., 2004).

Foram obtidos valores maiores para rendimento comercial de carcaça (RCC) para os animais confinados $(\mathrm{P}<0,05)$, sem diferença para rendimento verdadeiro de carcaça (RVC), provavelmente por um maior enchimento gástrico proporcionado pela pastagem. Esses valores foram compatíveis com a literatura (Grande et al., 2003; Hashimoto et al., 2007; Carvalho Jr. et al., 2009), que, avaliando animais Boer e seus cruzamentos, obtiveram valores entre $51,80 \%$ e $57,71 \%$ para RVC e de $43,26 \%$ e $48,78 \%$ para RCC.

Carvalho Jr. et al. (2009) afirmaram que o peso dos órgãos internos, influenciados pela nutrição, são fatores que alteram o rendimento da carcaça, visto que o aumento no teor de fibra da dieta eleva o tempo de retenção do alimento no trato gastrintestinal, explicando o menor rendimento comercial de carcaça dos animais semiconfinados, com acesso à pastagem, mas não do rendimento verdadeiro, que desconta o conteúdo gastrintestinal ao fazer o cálculo. 
Tabela 2. Médias e coeficiente de variação (CV) para peso vivo ao abate (kg) e características quantitativas de carcaças de cabritos Saanen confinados, Saanen semiconfinados e 7/8 Boer - 1/8 Saanen semiconfinados

\begin{tabular}{crrrrrr}
\hline & \multicolumn{3}{c}{ Sistema de terminação } & \multicolumn{3}{c}{ Grupo genético $^{2}$} \\
\hline Variável & \multicolumn{1}{c}{ SC } & SSC & EPM & SSC & BSC & EPM \\
\hline PVA (kg) & $30,67 \mathrm{a}$ & $27,18 \mathrm{~b}$ & 2,34 & $27,18 \mathrm{~A}$ & $27,98 \mathrm{~A}$ & 2,47 \\
PCQ (kg) & $13,64 \mathrm{a}$ & $11,16 \mathrm{~b}$ & 1,22 & $11,16 \mathrm{~A}$ & $11,56 \mathrm{~A}$ & 1,34 \\
RVC $(\%)$ & $51,86 \mathrm{a}$ & $50,95 \mathrm{a}$ & 1,24 & $50,95 \mathrm{~A}$ & $50,85 \mathrm{~A}$ & 1,07 \\
RCC (\%) & $43,54 \mathrm{a}$ & $40,20 \mathrm{~b}$ & 1,71 & $40,20 \mathrm{~A}$ & $40,31 \mathrm{~A}$ & 2,08 \\
ICC & $0,21 \mathrm{a}$ & $0,18 \mathrm{~b}$ & 0,01 & $0,18 \mathrm{~A}$ & $0,18 \mathrm{~A}$ & 0,02 \\
ICP & $0,43 \mathrm{a}$ & $0,41 \mathrm{a}$ & 0,02 & $0,41 \mathrm{~A}$ & $0,44 \mathrm{~A}$ & 0,03 \\
NCC $(\%)$ & $12,05 \mathrm{a}$ & $9,96 \mathrm{~b}$ & 0,71 & $9,96 \mathrm{~A}$ & $10,52 \mathrm{~A}$ & 0,70 \\
\hline
\end{tabular}

PVA: peso vivo ao abate; PCQ: peso da carcaça quente; RVC: Rendimento verdadeiro de carcaça; RCC: Rendimento comercial de carcaça; ICC: Índice de compacidade da carcaça; ICP: Índice de compacidade da perna; NCC: não constituintes de carcaça. SC: Saanen confinados; SSC: Saanen semiconfinados; BSC: 7/8 Boer - 1/8 Saanen semiconfinados. EPM: erro padrão da média. Letras diferentes na mesma linha, minúsculas para sistema de terminação e maiúsculas para grupo genético, indicam contraste significativo pelo teste $\mathrm{F}$ a $5 \%$ de probabilidade $(\mathrm{P}<0,05)$.

Os índices de compacidade da carcaça (ICC) apresentaram diferença significativa $(\mathrm{P}<0,05)$ entre sistemas de terminação, com o maior valor obtido para os animais confinados. Para o índice de compacidade da perna (ICP), não foram observadas diferenças entre tratamentos $(\mathrm{P}>0,05)$. Os índices de compacidade demonstram a musculosidade da carcaça, portanto valores mais elevados são os mais adequados.

Os valores observados por outros autores (Hashimoto et al., 2007, Carvalho Jr. et al., 2009; Menezes et al., 2009; Costa et al., 2010), entre 0,16 e 0,26 para ICC, foram semelhantes aos obtidos neste estudo. Para ICP, valores entre 0,36 e 0,40 foram observados, inferiores aos obtidos neste experimento, em que não foram observadas diferenças significativas para sistemas de terminação, nem para grupos genéticos (Tab. 2). Com o aumento do peso vivo ao abate, há melhora nos índices de compacidade da carcaça (Bonvillani et al., 2010).

Os elementos não constituintes de carcaça (NCC), representados em porcentagem, compreendem as porções comestíveis ou não comestíveis do animal, sendo constituídos por sangue, pele, trato gastrintestinal, cabeça, patas, rins em conjunto com a gordura perirrenal, fígado, coração, baço, aparelho reprodutor em conjunto com bexiga e aparelho respiratório.
Neste estudo observou-se diferença quanto a esse parâmetro (NCC) apenas para sistemas de terminação, no qual os animais confinados apresentaram um maior valor para essa característica $(\mathrm{P}<0,05)$, demonstrando que há um maior desenvolvimento das vísceras com o aumento do peso vivo do animal, decorrente do sistema de confinamento.

Para sistemas de terminação, houve diferença significativa para a área AOL (Tab. 3), na qual o grupo de animais confinados apresentou valor maior, demonstrando que há influência da alimentação sobre essa medida. Os valores obtidos no presente estudo, exceto para os cruzados Boer, se mostraram mais baixos que os observados na literatura, que variaram entre $5,30 \mathrm{~cm}^{2}$ a $14,56 \mathrm{~cm}^{2}$ (Silva Sobrinho e Neto, 2004; Grande et al., 2003; Silva Sobrinho, 2005), demonstrando que a raça Saanen, mesmo em sistema intensivo, não apresenta grande desenvolvimento muscular, devido à sua não especificidade para produção de carne. A grande variação observada na literatura ocorre em função dos diferentes pesos ao abate. A análise da área de olho de lombo é a medida mais representativa da quantidade e da qualidade da massa muscular no animal; portanto, valores maiores dessa medida representam as melhores carcaças, em quantidade de músculo (Hashimoto et al., 2007). 
Tabela 3. Médias e desvios padrão para as características qualitativas do lombo de cabritos Saanen confinados, Saanen semiconfinados e 7/8 Boer - 1/8 Saanen semiconfinados

\begin{tabular}{lrrrrrr}
\hline & \multicolumn{5}{c}{ Sistema de terminação } & \multicolumn{2}{c}{ Grupo genético } \\
\hline Variável & \multicolumn{1}{c}{ SC } & \multicolumn{1}{c}{ SSC } & EPM & \multicolumn{1}{c}{ SSC } & \multicolumn{1}{c}{ BSC } & EPM \\
\hline AOL $\left(\mathrm{cm}^{2}\right)$ & $5,27 \mathrm{a}$ & $4,02 \mathrm{~b}$ & 0,63 & $4,02 \mathrm{~B}$ & $5,65 \mathrm{~A}$ & 0,99 \\
Medida A $(\mathrm{mm})$ & $43,96 \mathrm{a}$ & $40,96 \mathrm{a}$ & 2,94 & $40,96 \mathrm{~A}$ & $44,23 \mathrm{~A}$ & 4,20 \\
Medida B $(\mathrm{mm})$ & $23,49 \mathrm{a}$ & $21,30 \mathrm{a}$ & 2,93 & $21,30 \mathrm{~A}$ & $22,74 \mathrm{~A}$ & 2,92 \\
Medida C (mm) & $0,84 \mathrm{a}$ & $0,71 \mathrm{a}$ & 0,22 & $0,71 \mathrm{~A}$ & $0,86 \mathrm{~A}$ & 0,25 \\
Medida J $(\mathrm{mm})$ & $1,41 \mathrm{a}$ & $1,02 \mathrm{a}$ & 0,39 & $1,02 \mathrm{~A}$ & $1,52 \mathrm{~B}$ & 0,40 \\
\hline & & & & & & \\
\hline PC $(\%)$ & $27,49 \mathrm{a}$ & $22,91 \mathrm{a}$ & 5,19 & $22,91 \mathrm{~A}$ & $21,18 \mathrm{~A}$ & 5,93 \\
FC $\left(\mathrm{kgf} \mathrm{cm}{ }^{-2}\right)$ & $6,13 \mathrm{~b}$ & $4,70 \mathrm{a}$ & 0,90 & $4,70 \mathrm{~A}$ & $4,86 \mathrm{~A}$ & 0,75 \\
\hline Músculo $(\%)$ & $63,87 \mathrm{a}$ & $65,87 \mathrm{a}$ & 3,82 & $65,87 \mathrm{~A}$ & $68,26 \mathrm{~A}$ & 3,59 \\
Osso $(\%)$ & $17,28 \mathrm{a}$ & $19,24 \mathrm{a}$ & 4,85 & $19,24 \mathrm{~A}$ & $19,34 \mathrm{~A}$ & 4,85 \\
Gordura $(\%)$ & $18,84 \mathrm{a}$ & $14,85 \mathrm{~b}$ & 2,41 & $14,85 \mathrm{~A}$ & $12,39 \mathrm{~A}$ & 2,55
\end{tabular}

AOL: Área de olho de lombo; Medida A - distância máxima no corte transversal do músculo Longissimus dorsi, no sentido centro-lateral da coluna vertebral; Medida B - distância da profundidade do músculo Longissimus dorsi, no sentido dorso-ventral do animal, perpendicular à medida $\mathrm{A}$; Medida $\mathrm{C}$ ou espessura da gordura de cobertura espessura de gordura sobre a secção do Longissimus dorsi, tomado à continuação da medida $\mathrm{B}$; Medida $\mathrm{J}$ - espessura máxima de gordura de cobertura no perfil do lombo; PC: Perda por cocção; FC: Força de cisalhamento; SC: Saanen confinados; SSC: Saanen semiconfinados; BSC: 7/8 Boer - 1/8 Saanen semiconfinados. EPM: erro padrão da média. Letras diferentes na mesma linha, minúsculas para sistema de terminação e maiúsculas para grupo genético, indicam contraste significativo pelo teste $\mathrm{F}$ a $5 \%$ de probabilidade $(\mathrm{P}<0,05)$.

Para as medidas A, B e C não foram observadas diferenças $(\mathrm{P}>0,05)$. Os comprimentos maior e menor do músculo Longissimus dorsi são úteis para a avaliação da quantidade de músculo presente na carcaça, sendo significativamente relacionados com a área de olho-de-lombo (Hashimoto et al., 2007). Para a espessura máxima de gordura, os animais cruzados 7/8 Boer - 1/8 Saanen apresentaram um valor maior $(\mathrm{P}<0,05)$, mostrando que o cruzamento com a raça Boer proporciona maior deposição de gordura. Os valores do EPM foram elevados para as medidas $\mathrm{C}$ e $\mathrm{J}$, pela diferença visível na quantidade de gordura da carcaça.

Kadim et al. (2003), ao estudarem 42 cabritos de três raças do Omani, em sistema extensivo com suplementação de concentrado, abatidos com um ano de idade (31kg de PV médio), observaram valores médios para medida $\mathrm{A}$ e medida $\mathrm{B}$, de $57,6 \mathrm{~mm}$ e $27,7 \mathrm{~mm}$, respectivamente; acima dos obtidos neste estudo. A AOL, correlacionada com essa medida, também se mostrou abaixo dos valores observados na literatura (Kadim et al., 2003; Hashimoto et al., 2007), confirmando a não especificidade para produção de carne da raça Saanen.
Os valores de perda por cocção (PC) não apresentaram diferença entre os tratamentos (Tab. 3), estando próximos aos observados por Freitas (2009), de 29,12\%, trabalhando com animais Saanen e 3/4 Boer - 1/4 Saanen, abatidos em média aos 157 dias de vida, com aproximadamente $29 \mathrm{~kg}$. Dhanda et al. (2003) afirmaram que valores mais altos para essa característica estão relacionados ao pH baixo na carcaça, que propicia a formação da carne PSE (pale, soft, exsudative). Os valores observados no presente estudo não foram elevados, concluindo-se que, apesar de não avaliada essa característica, não houve alteração significativa no valor do $\mathrm{pH}$ final da carne.

Houve diferença $(\mathrm{P}<0,05)$ para força de cisalhamento (FC), que está relacionada com a resistência da fibra muscular, em que o grupo confinado apresentou o maior valor para essa característica entre os sistemas de terminação, possivelmente por apresentar um valor mais elevado de PC, o que influencia na maciez da carne. Porém, todos os tratamentos apresentaram carne considerada macia; pois, segundo Costa et al. (2008), a carne é classificada como macia, com valores de força de cisalhamento até $8 \mathrm{kgf}$ 
$\mathrm{cm}^{-2}$; aceitável, de 8 a $11 \mathrm{kgf} \mathrm{cm}^{-2}$, e dura, acima de $11 \mathrm{kgf} \mathrm{cm}^{-2}$.

Ding et al. (2010), ao estudarem cabritos Guanzhong leiteiro puros e seus cruzamentos com Boer (1/2 Boer - 1/2 Guanzhong; 3/4Boer $1 / 4$ Guanzhong e 7/8 Boer - 1/8 Guanzhong), em sistema extensivo com acesso livre a péletes de leucena e abatidos aos 6, 8 e 10 meses de idade, observaram valores de FC maiores para os cabritos puros $\left(6,26 \mathrm{kgf} \mathrm{cm}^{-2}\right)$ e aumento linear para essa característica com o aumento da idade

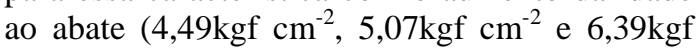
$\mathrm{cm}^{-2}$ para 6,8 e 10 meses, respectivamente), mostrando que a idade influencia na maciez da carne.

As porcentagens de osso e de músculo não apresentaram diferença $(\mathrm{P}>0,05)$ entre os tratamentos. Alguns estudos obtiveram valores entre $17,8 \%$ a $24,3 \%$ e $59,8 \%$ a $66,3 \%$ ((Sañudo et al., 2000; Almeida Jr. et al., 2004; Cunha et al., 2007)) para as variáveis citadas, respectivamente; intervalo que compreende os dados deste estudo.

Para gordura (\%), nos sistemas de terminação, foram obtidas porcentagens maiores para o grupo de animais confinados ( $\mathrm{P}>0,05)$ (Tab. 3), assemelhando-se aos resultados encontrados na literatura, que variam de $6,4 \%$ a $18,7 \%$ (Almeida Jr. et al., 2004; Hashimoto et al., 2007; Costa et al., 2008; Freitas, 2009). Segundo Macedo et al. (2008), a gordura auxilia na sensação de maciez da carne e protege a carcaça no momento da refrigeração, e pode sofrer mais influência em função do manejo alimentar do que da genética.

Segundo Menezes et al. (2009), os tecidos do lombo, músculo, gordura e osso tendem a aumentar com o avançar da idade do animal, acompanhando o crescimento e aumento de peso da carcaça; portanto, ao estudar esses componentes, pode-se extrapolar os resultados para a carcaça como um todo.

O aumento no teor de gordura na carcaça não proporcionou diferença significativa nas porcentagens de osso e músculo, provavelmente pelo elevado EPM do osso (Tab. 3). Porém, entre sistemas de terminação pôde-se observar uma tendência de redução na proporção de osso (\%) com o aumento da gordura (\%). Já entre grupos genéticos, a menor porcentagem de gordura observada no 7/8 Boer - 1/8 Saanen acarretou em uma maior porcentagem de músculo nesses animais.

A composição centesimal das amostras do músculo Longissimus dorsi (Tab. 4) apresentou diferença nos teores de umidade e de extrato etéreo (EE), para sistemas de terminação, e do teor de matéria mineral, para os grupos genéticos. $\mathrm{O}$ teor de umidade foi menor para os animais Saanen confinados $(\mathrm{P}<0,05)$, o valor de EE (\%) apresentou-se maior para os animais confinados, confirmando que a alimentação exerce influência também sobre a deposição de gordura no músculo.

Tabela 4. Médias e coeficiente de variação (CV) para umidade (\%), matéria mineral (\% MS), proteína bruta (\% MS) e extrato etéreo (\% MS) de amostras de Longissimus dorsi de cabritos Saanen confinados, Saanen semiconfinados e 7/8 Boer - 1/8 Saanen semiconfinados

\begin{tabular}{lrrrrrr}
\hline & \multicolumn{3}{c}{ Sistema de terminação } & \multicolumn{2}{c}{ Grupo genético } \\
\hline Variável & \multicolumn{1}{c}{ SC } & \multicolumn{1}{c}{ SSC } & EPM & \multicolumn{1}{c}{ SSC } & \multicolumn{1}{c}{ BSC } & EPM \\
\hline Umidade (\%) & $77,89 \mathrm{a}$ & $79,54 \mathrm{~b}$ & 1,07 & $79,54 \mathrm{~A}$ & $78,13 \mathrm{~A}$ & 1,10 \\
Matéria mineral (\%) & $1,46 \mathrm{a}$ & $1,59 \mathrm{a}$ & 0,06 & $1,59 \mathrm{~A}$ & $1,98 \mathrm{~B}$ & 0,09 \\
Proteína bruta (\%) & $16,17 \mathrm{a}$ & $16,88 \mathrm{a}$ & 0,38 & $16,88 \mathrm{~A}$ & $16,74 \mathrm{~A}$ & 0,44 \\
Extrato etéreo (\%) & $5,48 \mathrm{a}$ & $3,55 \mathrm{~b}$ & 0,10 & $3,55 \mathrm{~A}$ & $3,38 \mathrm{~A}$ & 0,14 \\
\hline
\end{tabular}

MM: Matéria Mineral; PB: Proteína bruta; EE: Extrato etéreo ${ }^{2}$ SC: Saanen confinados; SSC: Saanen semiconfinados; BSC: 7/8 Boer - 1/8 Saanen semiconfinados. EPM: erro padrão da média. Letras diferentes na mesma linha, minúsculas para sistema de terminação e maiúsculas para grupo genético, indicam contraste significativo pelo teste $\mathrm{F}$ a $5 \%$ de probabilidade $(\mathrm{P}<0,05)$.

Os valores do teor de umidade e extrato etéreo mostraram-se próximos aos observados por Grande et al. (2009), de $74,1 \%$ e $4,6 \%$, respectivamente, ao trabalharem com cabritos $3 / 4$ Boer - 1/4 Saanen, com peso inicial de $22,7 \mathrm{~kg}$ e 90 dias de idade, abatidos com $30,9 \mathrm{~kg}$ de peso 
vivo médio aos 61 dias de confinamento, para o tratamento controle (feno de aveia, farelo de soja, milho moído e suplemento mineral) de animais 3/4 Boer - 1/4 Saanen confinados. Ding et al. (2010), ao estudarem cabritos Guanzhong leiteiro puros e seus cruzamentos com Boer, observaram valores maiores de EE em animais puros Guanzhong leiteiro $(4,8 \%)$ que em cruzados 1/2 Boer - 1/2 Guanzhong leiteiro $(3,7 \%)$.

Não foram observadas diferenças $(\mathrm{P}>0,05)$ para os teores de proteína bruta (PB) da carne de cabritos entre os tratamentos (Tab. 4). Os teores de PB obtidos por Ding et al. (2010) foram maiores em animais cruzados, média de 20,39\%, acima dos observados no presente estudo.

\section{CONCLUSÕES}

Os sistemas de terminação confinamento e semiconfinamento exercem influência sobre as características de carcaça. Caprinos machos da raça Saanen podem ser utilizados para a produção de carne quando submetidos ao confinamento.

\section{REFERÊNCIAS}

AGRICULTURAL and food research council AFRC. Energy and protein requirements of ruminants. Farnham Royal: CAB International, 1995. 59p.

ABULARACH, M.L.S; ROCHA, C.E.; FELÍCIO, P.E. Características de qualidade do contrafilé (m. L. dorsi) de touros jovens da raça nelore. Cienc. Tecnol. Aliment., v.18, p.205-210, 1998.

ALMEIDA JR, G.A.; COSTA, C.; MONTEIRO, A.L.G. et al. Qualidade da carne de cordeiros criados em creep feeding com silagens de grãos úmidos de milho. Rev. Bras. Zootec., v.33, p.1039-1047, 2004.

BONVILLANI, A.; PEÑA, F.; GEA, G. et al. Carcass characteristics of Criollo Cordobés kid goats under an extensive management system: Effects of gender and liveweight at slaughter. Meat Science, v.86, p.651-659, 2010.
CARVALHO JR, A.M.; FILHO, J.M.P.; SILVA, R.M. et al. Efeito da suplementação nas características de carcaça e os componentes não carcaça de caprinos F1 Boera x SRD terminados em pastagem nativa. Rev. Bras. Zootec., v.38, p.1301-1308, 2009.

CASEY, N.H.; WEBB, E.C. Managing goat production for meat quality. Small Rum. Res., v.89, p.218-224, 2010.

COSTA, R.G.; MEDEIROS, A.N.; MADUGA, M.S. et al. Qualidade da carcaça de caprinos Saanen alimentados com diferentes níveis de volumoso e concentrado. Rev. Bras. Cienc. Agr., v.3, p.186-190, 2008.

COSTA, R.G.; VALLEJO, M.E.C.; BERMEJO, J.V.P. et al. Influência do sexo do animal e do sistema de produção nas características de carcaça de caprinos da raça Blanca Serrana Andaluza. Rev. Bras. Zootec., v.39, p.382-386, 2010.

CUNHA, E.A.; BUENO, M.; RODRIGUES, C.F.C. et al. Desempenho e características de carcaça de Cabritos Saanen e Mestiços Boer x Saanen abatidos com diferentes pesos. O Berro, v.45, p.76-81, 2007.

DHANDA, J.S.; TAYLOR, D.G.; MURRAY, P.J. Growth, carcass and meat quality parameters of male goats: effects os genotype and liveweigth at slaughter. Small Rumin. Res., v.50, p.57-66, 2003.

DING, W.; KOU, L.; CAO, B. et al. Meat quality parameters of descendents by grading hybridization of Boer goat and Guanzhong Dairy goat. Meat Science, v.84, p.323-328, 2010.

FREITAS, H.S. Produção de carne de cabritos e digestibilidade utilizando levedura seca (Saccharomyces cerevisae). 54f. 2009. Dissertação (mestrado em Zootecnia) Universidade Estadual de Maringá, Programa de pós-graduação em Zootecnia, área de concentração: Produção Animal, 2009.

GRANDE, P.A.; ALCALDE, C.R.; MACEDO, F.A.F. et al. Desempenho e características de carcaça de cabritos da raça Saanen recebendo rações com farelo de glúten de milho e/ou farelo de soja. Acta Scient. An. Sci., v.25, p.315-321, 2003. 
GRANDE, P.A.; ALCALDE, C.R.; LIMA, L.S. et al. Características quantitativas da carcaça e qualitativas do músculo Longissimus dorsi de cabritos 3/4 Boer $+1 / 4$ Saanen confinados recebendo rações contendo grãos de oleaginosas. Rev. Bras. Zootec., v.38, p.1104-1113, 2009.

HASHIMOTO, J.H.; ALCALDE, C.R.; SILVA, K.T. et al. Características de carcaça e da carne de caprinos Boer x Saanen confinados recebendo rações com casca de grão de soja em substituição ao milho. Rev. Bras. Zootec., v.36, p.165-173, 2007.

KADIM, I.T.; MAHGOUB, O.; AL-AJMI, D.S. et al. An evaluationof the growth, carcass and meat quality of characteristics of Omani goats breeds. Meat Science, v.66, p.203-210, 2003.

MACEDO, V.P.; GARCIA, C.A.; SILVEIRA, A.C. et al. Composição tecidual e química de cordeiros alimentados com rações contendo semente de girassol em comedouros privativos. Rev. Bras. Zootec., v.37, p.1860-1868, 2008.

MAHGOUB, O.; LODGE, G.A. A comparative study on grouth, body composition and carcass tissue distribution in Omani sheep and goats. $J$. Agric. Sci., v.131, p.329-339, 1998.

MEDIA Cybernetics. Image-Pro Plus application notes. Silver Spring: Media Cybernetics; 2002.

MENEZES, J.J.L.; GONÇALVES, H.C.; RIBEIRO, M.S. et al. Efeitos do sexo, grupo racial e da idade ao abate nas características de carcaça e maciez da carne de caprinos. Rev. Bras. Zootec., v.38, p.1769-1778, 2009.

OSÓRIO, J.C.S. Estudio de la calidad de canales comercializadas en el tipo ternasco segun la procedencia: bases para la mejora de dicha calidad em Brazil. 1992. 335p. Tese (Doutorado em Veterinária) - Facultad de Veterinaria, Universidad de Zaragoza.
SAÑUDO, C.; ALFONSO, M.; SÁNCHEZ, A.; DELFA, R.; TEIXEIRA, A. Carcass and meat quality in light lambs from different fat classes in the EU carcass classification system. Meat Science, v.56 p.89-94, 2000.

SILVA, D.J.; QUEIROZ, A.C. Análise de alimentos. Métodos químicos e biológicos. 3.ed. Viçosa, MG:Universidade Federal de Viçosa, 2002. 235p.

SILVA SOBRINHO, A.G.; SILVA, A.M.A.; GONZAGA NETO, A. et al. Parâmetros qualitativos da carcaça e da carne de cordeiros submetidos a dois sistemas de formulação de ração. Agr. C. Semi-arido, v.1, p.31-38, 2005.

SILVA SOBRINHO, A.G.; GONZAGA NETO, S. [2004]. Produção de carne caprina $e$ cortes da carcaça. Disponível em: <http://www.capritec.com.br/pdf/producao carnecaprina.pdf $>$. Acessado em: 16/11/2009.

SISTEMA de análises estatísticas e genéticas SAEG. Viçosa: UFV. 1997. 150p. (Manual do usuário).

STABLE MICRO SYSTEMS. User Manual. Texture Analyser TA XT2i, Godalming, versions 6.10 and 7.10. Fasdfafas: Stable Micro Systems, 1997.

WHEELER, T.L.; SCHACKELFORD, S.D.; KOOHMARAIE, E.M. Beef longissimus slice shear force measurement among steak locations and institutions. J. Anim. Sci., v.85, p.2283-2289, 2007.

YÁÑEZ, E.A.; RESENDE, K.T.; FERREIRA, A.C.D. et al. Utilização de medidas biométricas para predizer características da carcaça de cabritos Saanen. Revista Brasileira de Zootecnia, v.33, n.6, p.1564-1572, 2004. 